\title{
RACIONALIDADE EPISTÊMICA E O PARADOXO DE MOORE
}

Cláudio de Almeida*

RESUMO - G. E. Moore identificou uma forma surpreendente de irracionalidade epistêmica. Wittgenstein a chamou "o Paradoxo de Moore". Nenhum deles sabia, exatamente, do que estava falando. Mas, a vasta literatura sobre o problema se encarregou de mostrar sua importância. O que, no entanto, ainda não se havia notado, com suficiente clareza, é que o paradoxo está fortemente conectado a alguns dos debates mais fundamentais da agenda epistemológica contemporânea. Este artigo propõe uma resolução epistemológica ao problema e busca mostrar que o paradoxo ameaça, de forma contundente, as teses de fecho dedutivo da racionalidade epistêmica e do conhecimento, inutilizando as manobras contextualistas pró-fecho.

PALAVRAS-CHAVE - Paradoxo de Moore. Racionalidade Epistêmica. Conhecimento. Coerência. Fecho Dedutivo. Epistemologia do Raciocínio.
ABSTRACT - G. E. Moore identified a peculiar form of epistemic irrationality. Wittgenstein called it "Moore's Paradox". Neither of them knew exactly what he was talking about. And yet, the vast literature on the problem leaves no room for doubt: the paradox is deep; its resolution, elusive. But, up until now, we haven't been in a position to appreciate its importance for contemporary epistemology. This paper puts forward an epistemological solution to the paradox. It also seeks to show that the paradox yields counter-examples to deductive closure claims for both epistemic rationality and knowledge that are immune to contextualist proclosure maneuvers.

KEYWORDS - Moore's Paradox. Epistemic Rationality. Knowledge. Coherence, Deductive Closure. Epistemology of Reasoning.

\section{O paradoxo de Moore - como você ainda não o viu}

Diz a lenda, com base num relato de Norman Malcolm, que Wittgenstein considerava a descoberta que chamou "Paradoxo de Moore" como sendo a mais importante contribuição de G. E. Moore à Filosofia. A atenção que o problema recebe na obra de Wittgenstein torna a lenda plausível. E, a despeito de tudo o mais que há de venerável na obra de Moore, não

* Doutor em Filosofia, Professor do Programa de Pós-Graduação em Filosofia da PUCRS.

n. 2

maio/ago. 2009

p. $48-73$ 
é, mesmo, óbvio que Wittgenstein estivesse errado em sua avaliação da importância do paradoxo. Ao contrário, boa parte do meu objetivo neste artigo é argumentar em favor da tese de que o paradoxo talvez seja bem mais importante, para a agenda filosófica contemporânea, do que Wittgenstein podia supor no contexto intelectual em que estava localizado.

É certo que nem Moore, nem Wittgenstein estavam habilitados a compreender perfeitamente a extensão do problema. Isso não é matéria de debate. Ambos foram demasiado superficiais em suas análises do paradoxo. Embora eu não pretenda discutir suas análises aqui - não pretenda lhe dizer, exata e completamente, por que são insatisfatórias - eu devo dizer-lhe, ao menos, quais são algumas de suas maiores deficiências. ${ }^{1}$ Isso lhe é devido, porque eu pretendo mostrar-lhe, logo abaixo, que nem Moore, nem seu parceiro informal na discussão do problema, Wittgenstein, deram-nos condições de perceber o que é paradoxal no Paradoxo de Moore! Veja bem: eu não estou dizendo, apenas, que eles não solucionaram o problema. Eu estou, mesmo, dizendo-lhe que eles conheceram apenas parte do problema; não conheceram todo o problema.

Não há qualquer exagero na afirmação de que o Paradoxo de Moore foi completado por John N. Williams nos anos 90. Para ver como essa parceria inconsciente (no próprio Williams) e tardia se deu, reflita sobre as deficiências da compreensão mooreana/wittgensteiniana do problema como sugerido abaixo.

Moore observou que parece ser "absurda" a asserção de uma sentença como "Eu fui ao cinema ontem, mas não creio tê-lo feito". Nos escritos em que discute essa suposta absurdidade, ele não a distingue da absurdidade veiculada pela sentença "Eu fui ao cinema ontem, mas creio que não o fiz". ${ }^{2}$ Wittgenstein tampouco se importa com a diferença entre as proposições expressas por essas sentenças. ${ }^{3}$ De resto, para ambos, o fenômeno em questão diz respeito ao caráter aparentemente "absurdo" do ato de asserção de sentenças como essas. Agora, observe: A proposição expressa por uma sentença como "Chove, mas eu não creio que chova" causa perplexidade (naqueles que a percebem!) só porque o verbo "crer" é conjugado na primeira pessoa e no presente do indicativo! Conjugue-o em outra pessoa, ou em outro tempo verbal, e a perplexidade desaparece. Assim, se você faz uma asserção de "Chove, mas eu não acreditei que o

1 Para uma discussão da perspectiva wittgensteiniana sobre o paradoxo, cf. meu artigo 2001. A perspectiva mooreana é analisada em Green \& Williams 2007.

2 Cf. Moore 1942, 1944 e 1993.

3 Cf. Wittgenstein 1953 e 1980. 
tempo está chuvoso até sair de casa", o problema desaparece. O problema também desaparece quando uma sentença mooreana está encaixada em um condicional, por exemplo, ou em uma disjunção. Nenhuma excitação é provocada pela sentença "Se chove e eu creio que não chove, preciso encontrar uma previsão meteorológica mais confiável", porque, aqui, a sentença mooreana não é objeto de asserção. Do mesmo modo, veja como nada há de ofensivo, ceteris paribus, na asserção da (proposição expressa pela) seguinte sentença: "Ou chove e eu creio que não chove, ou você parou, finalmente, de me iludir sobre o tempo lá fora". E observe, ainda, que a suposta absurdidade não se confunde com a absurdidade de um caso de autocontradição. As sentenças em questão expressam proposições contingentes. Nós precisamos, então, compreender o que faz, a priori, "absurda" a asserção dessas proposições. (A asserção de qualquer proposição contingente pode ser "absurda", indevida, infeliz sob certas condições. Mas, é chocante que a asserção de uma dada proposição contingente seja "absurda" em quaisquer condições concebíveis). Esse é o Paradoxo de Moore na sua formulação histórica.

Mas, se isso é tudo que você vê naquelas sentenças mooreanas, você não vê tudo que elas contêm de problemático - e as condições estão criadas para uma análise deficiente do problema.

É preciso que se observe, de imediato, que a formulação histórica do problema dá importância indevida ao conceito de asserção. O que nos espanta num caso de asserção de uma proposição mooreana é o fato de que uma asserção é, no mais das vezes, a manifestação pública de um ato de crença, e o que o problema nos oferece é a consideração de um caso de aparente crença irracional em que a irracionalidade da crença se deve exclusivamente ao conteúdo aberrante da crença, sem que esse seja um caso de autocontradição - ainda que, segundo muitos (particularmente, aqueles que foram influenciados pela análise wittgensteiniana do problema) esse conteúdo seja, de alguma forma, aparentado à autocontradição, ou, mesmo, um caso de autocontradição implícita. ${ }^{4}$ Permita-me enfatizar esse ponto fundamental. Uma proposição mooreana é contingente: obviamente, pode ser verdadeiro que chove e que eu não creio que chova. O problema é que eu não posso crer nisso racionalmente! Mais uma vez, veja como isso é chocante: Se o que chamamos "conhecimento factual" (o conhecimento de fatos de qualquer espécie, inclusive fatos envolvendo objetos imateriais) é, pelo menos, a crença racional verdadeira (com alguma outra propriedade que a faça imune à deficiência revelada por Edmund Gettier), como

4 A proposta oferecida aqui pretende explicar, exatamente, o parentesco percebido entre a crença mooreana e a crença autocontraditória. 
se supõe ser, tradicionalmente, desde Platão, então, se é verdade que chove e eu não creio que chova, aí está um fato do qual eu não posso ter conhecimento enquanto ocorre! $\mathrm{Mas}$, se você pensar que o problema é, fundamentalmente, um problema de asserção absurda, e, não, de crença absurda, irracional, você então enfrentará a dificuldade aparentemente intransponível de explicar o que faz desse caso um caso de asserção absurda, sem que o conceito de crença irracional desempenhe um papel central em sua explicação. Não há tal explicação na literatura contemporânea. Por outro lado, parece óbvio que, se alguém tem uma crença mooreana desacompanhada de qualquer ato de asserção, essa pessoa tem uma crença "absurda", como diria Moore. Queremos, assim, saber em que consiste a "absurdidade" da crença mooreana. A explicação da absurdidade da asserção mooreana vem daí, de graça.

Mas, note: Até aqui, nada foi dito sobre por que as proposições que constituem o paradoxo devem ser percebidas como "absurdas", por que, exatamente, devemos pensar que são paradoxais e que, se você não as percebe como absurdas, paradoxais, o problema é seu! Se aceitarmos as teses segundo as quais uma proposição mooreana não é uma contradição e a "absurdidade" da proposição mooreana não é derivada da suposta absurdidade da asserção que a tem como conteúdo, porque isso nada explica sobre o fato mais fundamental de que sua crença mooreana é absurda mesmo quando não-manifestada num ato de asserção, então você não encontrará compreensão da absurdidade mooreana no que lhe dizem Moore e Wittgenstein sobre o fenômeno. E não é razoável pensar que, se o que faz daquelas proposições "absurdas" não lhe é aparente, você é um caso de pouca inteligência. ${ }^{6} \mathrm{O}$ paradoxo não é, sob esse aspecto, diferente de outros paradoxos importantes. Se alguém lhe disser que é irracional ter a crença cujo conteúdo é expresso por "Esta crença não é verdadeira", nada há de irrazoável no pedido por uma explicação da irracionalidade dessa crença. (A simples menção dessa crença pode não bastar para que você a considere irracional). Essa explicação toma a forma de um argumento cuja conclusão é a de que sua crença é verdadeira se e somente se não é verdadeira, o que é absurdo e parece depor, conclusiva e obviamente, contra a racionalidade da crença em questão,

5 Para uma introdução ao problema mais fundamental da agenda epistemológica contemporânea, o "problema de Gettier", cf. Robert Shope 1998.

6 Na edição de 2003 da Rutgers Epistemology Conference, a professora Catherine Elgin (Harvard University) confessou, publicamente, que não vê por que as proposições mooreanas devam ser consideradas absurdas. Essa é uma das pessoas de inteligência superior de quem já ouvi esse tipo de confissão - pessoas que, com certeza, desconhecem os argumentos que constituem o paradoxo, expostos abaixo. 
como você não terá dificuldade de compreender diante da exposição do argumento. ${ }^{7} \mathrm{O}$ mesmo pode ser dito do paradoxo que nos preocupa. É aí que John Williams entra em cena. E é aí que notamos a necessidade de uma discussão muito mais sofisticada do fenômeno que chamamos "Paradoxo de Moore". Essa discussão mais satisfatória vai mostrar, com clareza inédita, que o fenômeno é epistêmico.

Devemos, de imediato, observar que proposições mooreanas da forma

(i) $p$, mas eu não creio que $p$

são, sob um aspecto potencialmente importante, diferentes de proposições mooreanas da forma

(ii) $p$, mas eu creio que não- $p$,

o que muitos analistas, assim como o próprio Moore, deixaram de observar, ou deixaram de levar em conta em suas análises do problema. Como notou Williams, quem tiver uma crença que tenha como objeto tanto uma proposição da forma (i), quanto uma proposição da forma (ii), terá, necessariamente, uma crença falsa em seu sistema de crenças, mas as causas dessa posse necessária de uma falsidade são diferentes nesses casos. Para ver como crenças das formas (i) e (ii) garantem a inclusão de falsidades em seu sistema de crenças, suponha, como é tradicionalmente feito, que a crença se distribui sobre a conjunção, ou seja, que, se você crê que $p \& q$, então você crê que $p$ e crê que q. Observe, agora, que, se você crê em uma proposição da forma (i), você crê que p. Mas, nesse caso, a conjunção da forma (i) é falsa, já que sua crença de que $p$ falsifica o segundo conjunto da conjunção (segundo o qual você não crê que $p$ ). Portanto, uma crença da forma (i) é autorrefutadora. Assim, se verdadeira, a crença da forma (i) é falsa. Portanto, toda crença da forma (i) é falsa.

No outro caso, em vista do mesmo princípio de distribuição, se você tem uma crença da forma (ii), você, mais uma vez, crê que $p$. Agora, se a crença da forma (ii) é verdadeira, então você é inconsistente (isto é, tem crenças contraditórias), porque, se a conjunção é verdadeira, é fato que você também crê que não-p, conforme o segundo conjunto daquela conjunção. Necessariamente, uma de suas crenças é falsa. Assim, tanto crenças da forma (i) quanto crenças da forma (ii) asseguram a inclusão de uma falsidade no seu sistema de crenças. ${ }^{8}$

Com base nessa observação certeira, Williams pretende fundamentar a conclusão segundo a qual uma crença mooreana é irracional apenas

Sobre a "forma canônica" de um paradoxo, cf. meu artigo 2005.

8 Cf. Williams 1994, sua discussão mais ambiciosa do problema. 
porque compromete o agente com a posse de uma crença falsa. Mas, eu penso ter mostrado, em outras publicações sobre o assunto, que há várias boas razões para crer que aquela observação certeira não lhe dá a base conceitual para uma explicação satisfatória da irracionalidade mooreana. $^{9}$

Para nossos propósitos aqui, cumpre observar, em primeiro lugar, que, sejam quais forem seus méritos, uma explicação do fenômeno fundada apenas na observação de Williams é insatisfatória, porque é incompleta. A análise que Williams faz dos casos (i) e (ii) não permite explicar por que as formas

(iii) $p$, mas não é racional, para mim, crer que $p$

e

(iv) $p$, mas é racional, para mim, crer que não- $p$

parecem-nos tão "absurdas" quanto as formas (i) e (ii). Note que esses não são casos de autorrefutação ou inconsistência. Nem crenças da forma (iii), nem crenças da forma (iv) assegurariam a posse de crença falsa. ${ }^{10}$ Se $p$ é verdadeira, se é verdadeira minha autocrítica em (iii) e (iv) e se eu não consigo crer como julgo que deva segundo essa autocrítica, então nem (iii), nem (iv), por si sós, acrescentarão falsidades ao meu sistema doxástico. $\mathrm{E}$, ainda que ignoradas pela grande maioria dos autores que tratam do problema, (iii) e (iv) parecem, muito claramente, ser formas mooreanas. A minha crença de que $p$ é irracional em ambos os casos - dada a suposição de que minhas crenças das formas (iii) e (iv) são verdadeiras. No caso de (iii), eu creio verazmente que sou irracional ao crer que $p$. No caso de (iv), dada a suposição universalmente aceita de que eu não posso crer racionalmente em contraditórios, eu sou, mais uma vez, irracional ao crer que $p$. (Note que estamos trabalhando com a suposição de que as crenças das formas (iii) e (iv) são verdadeiras. $\mathrm{E}$ estamos concluindo que podem ser verdadeiras. Mas, são verdadeiras só se são irracionais. Essa característica de crenças é peculiar à absurdidade mooreana).

9 Cf. meus artigos 2001 e 2007b. Em resposta a meu artigo 2001, Williams alterou a sua proposta de resolução em Green \& Williams. Mas, esse detalhe não afeta o rumo de nossa discussão aqui.

10 Observe, também, que as formas (iii) e (iv) não são logicamente equivalentes. Do fato de que não é racional, para mim, crer que p, não se pode inferir que seja racional, para mim, crer que não-p. Pode ser que ambos, crer que $p$ e crer que não- $p$, não sejam casos de racionalidade para mim, porque eu talvez deva suspender o juízo quanto a $p$ (e não-p). Mas, segundo a tese (a) proposta na seção 3, abaixo, (iv) implica (iii). 
É possível que haja proposições contingentes de muitas outras formas que sejam, também, casos dessa forma de irracionalidade que chamamos "mooreana". Não parece haver critério sintático ou semântico que caracterize o fenômeno. Mas, devemos exigir que uma análise da absurdidade mooreana mostre, ao menos, por que crenças nas proposições das formas (i)-(iv) são casos de irracionalidade. É o que pretendo fazer a seguir.

Mas, observe, para concluirmos nossa discussão rápida da proposta de Williams, que, se você considera que a irracionalidade de uma crença da forma (ii) é derivada do fato de que, se verdadeira, essa crença põe uma falsidade no sistema doxástico do crente, nós ainda carecemos de uma explicação de por que isso torna aquela crença irracional. Não há essa explicação na obra de Williams. E não é fácil imaginar como tal explicação seria produzida em favor de Williams. Dado aquele princípio de distribuição da crença, e dada a suposição falibilista prevalente de que falsidade de uma dada crença não implica sua irracionalidade, qualquer crença conjuntiva falsa põe uma falsidade no sistema doxástico do crente. $\mathrm{E}$, por hipótese, essa crença conjuntiva pode ser racional. ${ }^{11}$

\section{Racionalidade epistêmica, inconsistência e incoerência}

Bem, já há um paradoxo diante de nós. Muito simplesmente: Há proposições contingentes que podem ser conteúdo de conhecimento para você, mas, não para mim, mesmo que você as comunique a mim em atos impecáveis de asserção e eu o tome, corretamente, como um asseridor veraz! $!^{12}$ Convenhamos, isso é chocante. Pode ser verdade que ambos, chove (em um dado momento) e eu não creio que chova (naquele momento). Você pode saber disso. Mas, eu não posso ser informado desse fato - não posso saber que é fato. Se eu acreditar nisso, a informação se torna falsa (caso em que, naturalmente, você também deixa de saber disso; mas, ao contrário do que se dá comigo, pode ter sabido). Esse é o nosso caso (i). Nos outros três casos, eu estou impedido de saber porque estou impedido de crer racionalmente (e não pode ser matéria de disputa entre epistemólogos que esse caso de irracionalidade impede que se produza o conhecimento). Você continua podendo saber o que eu não posso.

11 Cf. meus artigos 2001 e 2007b para a sugestão de que o modo como Williams pretende conectar racionalidade e autorrefutação, no caso de crenças da forma (i), também é um fracasso. De novo: a alteração que ele faz em sua proposta de 2007 (em Green \& Williams) não o protege contra essa objeção.

12 Eu simplifico a conversa ao identificar essa conclusão como sendo o paradoxo. $\mathrm{Na}$ verdade, o paradoxo é todo o argumento que tem essa constatação chocante como conclusão. Cf. a nota 7, acima. 
A explicação dessa situação bizarra - aquilo que deve contar como uma resolução do paradoxo, já que o bizarro é "solucionado" quando é desmistificado, compreendido - depende, eu proponho, da compreensão de como uma crença mooreana nos faz incoerentes. É isso que lhe ofereço no que segue, a partir de uma compreensão suficiente do que seja a incoerência.

Uma parte fundamental da tarefa do epistemólogo é explicar o fenômeno que designamos com o termo "irracionalidade", um fenômeno que tem, ao menos, duas formas identificadas na literatura especializada. ${ }^{13}$ Em sua forma mais bem- compreendida, uma crença é irracionalmente sustentada quando sua presença, no sistema de crenças de um agente doxástico qualquer, provoca a espécie de desarranjo do sistema que chamamos "incoerência". Em vez de lhe oferecer, aqui, uma definição desse termo filosófico, "incoerência", eu me basto com um exemplo que me parece suficientemente esclarecedor para os nossos propósitos: ${ }^{14}$ suponha que você crê que $(p)$ o mordomo é o assassino. E suponha, também, que essa sua crença está baseada nas suas crenças segundo as quais (q) a estatística policial revela que, em 99.9\% dos casos de assassinato em que o mordomo tem oportunidade e motivação para o crime, ele é o culpado, e $(r)$, no caso em questão, o mordomo tinha oportunidade e motivação. Mas, suponha, ainda, que você também crê que $(s)$ há uma testemunha que jura ter visto o mordomo a centenas de quilômetros da vítima na noite do crime. Se tudo que seu sistema de crenças contém sobre o crime são as crenças $p, q, r$ e $s$, o sistema é incoerente, porque ele abriga crenças que são contraevidência uma para a outra, $p$ e $s$. Estamos, supostamente, em um mundo em que é mais provável que $p$ seja falsa quando s é verdadeira e vice-versa (e a medida dessa probabilidade é irrelevante, é fundamental observar, mas a tração intuitiva do caso requer alta probabilidade epistêmica). Isso, afinal, é, mesmo, o que nossas intuições indicam nesse caso: há algo gravemente errado em sua vida mental, se todas as suas crenças relativas àquele crime formam o conjunto que tem apenas $p, q, r$ e $s$ como membros. Você não está intitulado a crer que $p$ quando seu sistema de crenças é incapaz de neutralizar o efeito solapador que a crença s tem sobre a legitimidade da manutenção da crença $p$ em seu sistema doxástico (porque $\mathrm{s}$, se verdadeira, torna $p$ menos provável, ceteris

13 Neste artigo, eu ignoro a forma de irracionalidade originada pela insuficiência da evidência que se tenha em favor de uma crença em uma determinada circunstância - assim como qualquer outra deficiência no processo de formação da crença.

14 Minha definição do termo é oferecida em De Almeida 2007b. A mais influente análise do conceito de coerência é dada em Keith Lehrer 2000. 
paribus, relativamente ao que você considera ser uma descrição veraz do mundo). Assim, falando tecnicamente, diremos que sua crença de que $p$ é incoerente com o sistema de crenças (o subconjunto próprio do conjunto que constitui a totalidade de suas crenças, digamos) cujas únicas crenças relevantes são q, $r$ e s. E, se uma crença é incoerente com seu sistema de crenças em um dado momento, ela é irracionalmente mantida naquele momento. (Elipticamente, diremos que "a crença é irracional", ou, mais dramaticamente, que "você é irracional").

Essa forma de irracionalidade - a irracionalidade gerada por aquela forma de conflito entre crenças, a incoerência - tem sido intensamente analisada na literatura epistemológica contemporânea (e eu não pretendo sugerir que a brevíssima explicação acima seja resultado consensual na comunidade, mesmo que haja, como há, muito poucos que a questionariam). ${ }^{15}$ Muito menos familiar é a forma de irracionalidade resultante, exclusivamente, do conteúdo de uma determinada crença. Veja bem: não mais se trata, aqui, daquela forma peculiar de "conflito" entre crenças discutida acima, o caso mais óbvio da incoerência. Nossa questão é: Pode, tão-somente, o conteúdo de uma crença torná-la irracional?

Não deve haver dúvida de que nós queremos responder que sim. Há uma espécie de conteúdo (uma espécie de proposição) que nós mesmo os menos sofisticados de nós - pensamos não possa ser objeto de crença racional: a contradição (qualquer proposição logicamente equivalente a uma conjunção da forma $p \& n a ̃ o-p)$. A grande maioria de nós (humanos) reage com sobrancelhas levantadas a uma afirmação séria (e não-metafórica) de que, por exemplo, chove e não chove aqui e agora. É interessante observar, no entanto, que, a despeito da banalidade dessa observação, a maioria dos epistemólogos explicaria de forma insatisfatória a irracionalidade da crença em uma contradição, se você os confrontasse com esse pedido de explicação. Vale a pena, aqui, nós nos determos um pouco nessa dificuldade antes de examinarmos o outro caso interessante de irracionalidade causada exclusivamente pelo conteúdo da crença.

A resposta decepcionante que você, muito provavelmente, obteria é a seguinte: "Uma contradição implica logicamente qualquer proposição (segundo a lógica clássica). Assim, dada a suposição corriqueira de que a implicação lógica transmite, para a proposição implicada, a racionalidade da crença na proposição implicadora, se você crê racionalmente em uma contradição, você fica intitulado a crer racionalmente em qualquer absurdo

15 Talvez Richard Foley seja o único epistemólogo influente cujas teses fundamentais dão margem ao afrouxamento da relação entre incoerência e irracionalidade. Cf. Foleym 1993. 
(já que toda proposição é implicada por uma contradição, inclusive os mais horrendos absurdos). Mas, você não pode crer racionalmente que, por exemplo, você criou o universo na última segunda-feira. E não apenas porque segunda-feira é o seu dia de folga! Logo, você não pode crer racionalmente numa contradição". ${ }^{16}$

Qual é o problema com essa explicação? É que esse epistemólogo se esqueceu de Descartes! A tração do argumento depende da premissa que - sob a força retórica da alegação de "absurdidade" - estabelece o compromisso com a tese de que, necessariamente, dada a evidência disponível, você deve crer que seja irracional a crença de que você é o criador do universo. Mas, numa linha cartesiana, você replicaria assim: "Há algum tempo, eu me senti extraordinariamente poderoso e me vi jogando uma bola para o alto. Tão logo deixou a minha mão, a bola explodiu, gerando uma espessa poeira. Eu, então, pensei: 'Acabo de criar o universo, e hoje é uma segunda- feira'. Em outro momento, eu me vi numa aula de filosofia - com todas as fraquezas de um ser humano normal. E o professor estava interessado em discutir os sonhos mais fantásticos. Em que momento seria irracional crer que eu sou o criador do universo? Certamente, não no primeiro momento, já que, lá, eu tinha, por hipótese, excelentes razões para crer que eu sou o criador do universo! Não é, portanto, óbvio que eu não seja o criador do universo - a menos que seja óbvio que a experiência de ter sido o criador seja ilusória e que a experiência do relato de um sonho absurdo seja verídica.

"Você pode, é verdade, fazer-nos complicar essa conversa, se observar que é patentemente absurdo crer, por exemplo, que $2+2=5$, o que também é logicamente implicado por uma contradição, mas não conseguirá obter resultado diferente. Nesse caso, eu teria de invocar algum dos muitos casos incríveis de aparente conhecimento a priori. Bertrand Russell, por exemplo, fez-nos ver que, de certas proposições aparentemente irrecusáveis sobre conjuntos, uma contradição é acarretada. ${ }^{17} \mathrm{E}$ você veria que, no caso do assim-chamado "Paradoxo de Russell", o que nós somos obrigados a recusar parece ser tão irrecusável quanto a falsidade de " $2+2=5$ "! Nós cremos, é certo, como o próprio Russell, que o raciocínio

${ }^{16}$ Na literatura contemporânea, um argumento influente, nessa linha, foi posto em circulação por Karl Popper em seu artigo de 1940. Mas, não há, nesse artigo, qualquer referência explícita ao princípio de transmissibilidade da racionalidade através da implicação lógica (um princípio de fecho epistêmico). Nem mesmo o conceito de racionalidade é explicitamente invocado na construção do argumento - que se destina, apenas, a defender a rejeição de teorias que incorporem enunciados contraditórios (ou a conjunção deles, uma contradição).

17 Para uma excelente discussão introdutória ao problema, veja R. M. Sainsbury 1995. 
que engendra aquele paradoxo tem de ser falacioso. Mas, a menos que sejamos capazes de produzir uma argumentação persuasiva que revele o motor da falácia, o mais razoável, aparentemente, seria concluirmos que é racional crermos em, ao menos, algumas contradições. Isso é, no entanto, exatamente o que desejamos evitar. ${ }^{18}$ Mas, para que essa postura não seja assumida dogmaticamente, nós precisamos ter um argumento convincente contra a racionalidade da crença em contradições. (Tal argumento nos ofereceria, ao menos, o refúgio da suspensão racional de juízo, enquanto dragões conceituais como o Paradoxo de Russell não são abatidos). Assim, eu ainda não tenho qualquer boa razão para pensar que a crença em uma contradição é necessariamente irracional, se sua irracionalidade é percebida através de seu modus tollens. Mas, não há qualquer interesse filosófico em estabelecer que é, às vezes, irracional crer em uma contradição, já que isso é verdadeiro de qualquer proposição! O nosso problema é encontrarmos um arrazoado que sustente a convicção popular de que o compromisso intelectual com uma contradição é uma falha de racionalidade".

Você vence o primeiro round. Suponha, no entanto, que o epistemólogo decepcionante volte ao ataque com a seguinte resposta: "Você está sendo superficial! O problema, aqui, não é apenas o fato de que uma contradição acarreta (e, assim, nós estamos supondo, torna racional as crenças em) proposições contingentes bizarras e qualquer falsidade necessária. Vamos ignorar o fato de que uma contradição acarreta qualquer coisa. OK! Eu lhe concedo que esse não pode ser o problema. É verdade que, se é concebível que a crença em uma contradição seja racional, será difícil encontrar alguma implicação cuja irracionalidade seja óbvia, para alavancar o meu modus tollens popperiano. OK! O problema que eu reputo insuperável é que, se você tem uma crença da forma $p \& n a ̃ o-p$, você é inconsistente. Mas, ninguém pode ser ambos, racional e inconsistente, pode?! Logo, a crença em uma contradição não pode ser racional".

Sua resposta: "Antes de nós decidirmos se você está certo ao sustentar que ninguém pode ser racional e inconsistente num dado momento, observe: Você parece fazer a suposição questionável de que, se eu creio em uma proposição que acarreta uma contradição, eu sou inconsistente. Inconsistência é (pelo menos) a impossibilidade lógica de que um conjunto de proposições contenha só verdades num dado momento. E, se um conjunto de proposições contém uma contradição, ele não pode conter só

18 O lógico filosófico Graham Priest é um dos poucos que não pretende resistir à conclusão de que pode ser racional crer em contradições (porque haveria boas razões para crer que algumas delas são verdadeiras). Cf. Priestm 1986. Para uma discussão da relevância epistemológica do Paradoxo de Russell e da reação de Priest ao problema, cf. meu artigo 2007a. 
verdades. Mas, o fato de que eu creio em proposições que acarretam uma contradição não garante que eu tenha essa contradição como objeto de crença! Você diria que Frege era irracional ao crer no seu axioma 5 antes de ler aquela carta fatídica que lhe enviou Russell (a carta em que Russell lhe mostra como o axioma 5, juntamente com suposições banais, implica uma contradição)? Como diria Gilbert Harman (aproximadamente), Frege era, no máximo, indiretamente inconsistente, já que a contradição não residia em seu sistema de crenças. ${ }^{19}$ Ele nunca acreditou em uma contradição! Se nós decidirmos que a inconsistência indireta acarreta irracionalidade, não haverá muita racionalidade disponível para os humanos menos brilhantes que Frege! Claramente, então, se o problema é evitar a inconsistência direta, a crença em uma proposição que implique uma contradição não garante que eu tenha a contradição (ou os contraditórios que ela acarreta) em meu sistema de crenças.

"Agora, veja: Parece muito claro que uma falsidade necessária pode ser objeto de crença racional. Considere o caso de Graham Priest - e suponha que ele sustente que há contradições verdadeiras (seu "dialetismo"). Suponha, ainda, que você tem boas razões para crer que é o único membro da comunidade filosófica que conhece o erro na argumentação de Priest (o que bem pode ser o fruto do trabalho árduo de uma vida, recém-encontrado). Nesse caso, você tem boas razões para crer que a proposição expressa por "Priest está certo em seu dialetismo" é uma falsidade necessária, já que o dialetismo de Priest inclui a tese de que há contradições verdadeiras, e isso, se falso, é uma falsidade necessária. Mas, você não tem o direito de pensar que nós, estudiosos do trabalho de Priest que somos menos filosoficamente competentes que você, somos irracionais, digamos, ao suspender o juízo sobre se ele está certo em seu dialetismo. Mas, até aqui, nossa discussão parece indicar que eu posso ser, ao mesmo tempo, inconsistente e racional, já que a inclusão de qualquer falsidade necessária em meu sistema de crenças me faz inconsistente. Ainda assim, eu devo admitir que parece haver algo particularmente repulsivo na crença em contradições - algo que não está presente quando consideramos a crença em outros tipos de falsidade necessária. Como explicar isso?"

Você está em vantagem na disputa com ambos, aquele que supõe que é óbvio que não se pode crer racionalmente em contradições e aquele que pretende fundamentar a condenação à crença autocontraditória num princípio de fecho epistêmico. Mas, você está desconfortável com a idéia de que se possa racionalmente crer numa contradição. O que seria,

$\overline{19}$ Cf. Harmanm 1986. 
então, uma explicação que vindicasse a repulsa que nos causa a crença numa contradição?

Uma explicação que me parece satisfatória associa o princípio de distribuição da crença sobre conjunções (universalmente aceito na literatura epistemológica) a uma noção de inconsistência forte. Há, na literatura, o reconhecimento de uma distinção - para nós crucial - entre inconsistência forte e inconsistência fraca. Se você inclui contraditórios ou contrários lógicos (proposições das formas "Todo S é P" e "Nenhum $\mathrm{S}$ é $\mathrm{P}$ ") em seu sistema de crenças, você é fortemente inconsistente. Afora esses casos, qualquer outro caso de impossibilidade lógica de que todas as suas crenças sejam verdadeiras é um caso de inconsistência fraca. ${ }^{20}$ Essa distinção conceitual, em conluio com aquele princípio de distribuição, explica a nossa aversão muito especial à crença em contradições, a percepção de que você não pode ser racional quando crê em uma proposição da forma $p \&$ não- $p$. Em princípio, a racionalidade de uma crença parece ser incompatível apenas com o caso da inconsistência forte.

É necessário, ainda, observar que essa explicação pretende ser compatível com as suposições que fizemos ao discutir o caso do mordomo. Nós supusemos que racionalidade implica a ausência de incoerência. Essa suposição abarca perfeitamente o caso da crença em uma contradição da forma $p \& n a ̃ o-p$. Basta observar que eu não posso, num dado momento, crer que $p$ e crer, também, que não-p e ter um sistema coerente de crenças, já que uma dessas crenças é contraevidência para a outra, conforme as suposições que fizemos ao discutir o caso do mordomo. Se $p$ for verdadeira, então a probabilidade de que não-p seja, também, verdadeira é drasticamente reduzida (em qualquer mundo), já que passa a ser zero (e vice-versa). Portanto, eu não posso ter uma crença da forma $p \& n a ̃ o-p$ e ser coerente. Nós aceitamos, assim, que a inconsistência forte implica incoerência. Mas, nós também propomos que se reconheça a inconsistência fraca como uma propriedade que é compatível com a coerência. Se não me engano, isso não é reconhecido na literatura especializada, aparentemente porque, quando se observa que coerência implica consistência, ignora-se a distinção entre inconsistência forte e fraca. ${ }^{21}$ Mas, o nosso uso dessa distinção, aqui, parece ter um apelo intuitivo fortíssimo: Quando se considera o caso da crença em uma

${ }^{20}$ Para uma definição dos termos "inconsistência forte" e "inconsistência fraca", cf. meu artigo 2007b.

21 Richard Foley e Peter Klein não ignoram essa distinção quando atacam o conceito de coerência. Cf. Foley 1979 e Klein 1985. Eu estou sugerindo, portanto, que eles têm um problema aqui. 
falsidade necessária, só a crença autocontraditória é, necessariamente, acompanhada de crenças contraditórias. De resto, como vimos, nossa reação ao caso de Frege, por exemplo, impõe a compatibilização entre inconsistência fraca e racionalidade, e, por essa via, a compatibilização entre inconsistência fraca e coerência. Nosso uso daquela distinção não é, portanto, ad hoc.

Até aqui, nossa explicação daria conta só dos casos de crença em contradições da forma p\&não-p, porque se utiliza daquele princípio de distribuição para distinguir a crença autocontraditória da crença que tem como objeto outros tipos de falsidade necessária. ${ }^{22}$ É crucial, no entanto, observar que falsidades veritativo-funcionais se distinguem de outros tipos de falsidade necessária num aspecto epistemologicamente importante ainda não-observado aqui. Embora qualquer falsidade necessária acarrete qualquer proposição segundo a noção clássica de acarretamento, não há método de prova disponível que me permita, com um mínimo de plausibilidade (isto é, com o uso de regras de inferência aceitáveis), inferir da falsidade "847×68=57.586", por exemplo, que "Marte é um planeta". Contradições (de qualquer forma) não são como outras falsidades necessárias nesse aspecto, já que, de uma contradição, eu posso inferir, validamente, o que bem entender, utilizando regras de apelo universal. Isso não vale, no entanto, para qualquer falsidade necessária. Não há rota inferencial (sem apelo àquela perversa noção semântica clássica de validade) para a conclusão de que "Marte é um planeta" a partir da premissa segundo a qual $847 \times 68=57.586$. A observação de que esse é um argumento válido, somada à suposição falibilista de que eu creio racionalmente que $847 \times 68=57.586$, claramente, não bastam para que esse seja um caso de bom raciocínio! ${ }^{23}$ Assim, nós chegamos ao cerne de nossa explicação da irracionalidade da crença em contradições: Se você crê numa contradição, você abriga, em seu sistema de crenças, evidência para a inclusão de contraditórios no sistema. E essa é uma alegação que os recursos conceituais do nosso epistemólogo decepcionante não pareciam capazes de implicar, o que o impedia de superar suas objeções, ainda que aquele epistemólogo pretendesse produzir a conclusão que você também desejava obter.

22 Assim, se você crê que toda proposição autocontraditória é uma conjunção, como muitos fazem historicamente, você já tem uma explicação da irracionalidade da crença autocontraditória que não sucumbe às objeções que você apresentou ao epistemólogo decepcionante.

${ }^{23}$ Eu aceito, aqui, a suposição corriqueira segundo a qual, embora quase todas as regras de dedução aceitas classicamente tenham sido objeto de contestação filosófica interessante, essa contestação está longe de ser convincente para a grande maioria da comunidade filosófica. Cf. meu artigo 2007b, para uma discussão mais extensa da manobra argumentativa que faço aqui. 
Observe, finalmente, como nossa explicação da irracionalidade da crença autocontraditória é conceitualmente derivada das suposições que fizemos no caso do mordomo. O diagnóstico, naquele caso, é o de que você é incoerente porque, na terminologia de Lehrer, seu sistema de crenças dá margem a uma "objeção não-respondida" a sua crença de que o mordomo é o assassino. ${ }^{24}$ Aquela objeção não-respondida - derivada do fato de que você crê haver uma testemunha que isenta o mordomo, sem ter qualquer crença que faça a neutralização do impacto solapador desse testemunho - não é, ainda, evidência conclusiva de que sua crença na culpabilidade do mordomo é falsa. Mas, ela reduz a probabilidade de que sua crença de que $p$ seja verdadeira e, por isso, é, em alguma medida, mesmo que muito levemente, evidência para a crença de que não- $p$. No caso da crença autocontraditória, você possui evidência acarretadora para crer em contraditórios. A evidência - assim como a racionalidade vem em graus. Incoerência, no entanto, não é um estado gradual. Tanto no caso do mordomo, quanto no caso da crença autocontraditória, você é incoerente. $\mathrm{E}$, em ambos, é o mesmo estado de incoerência que o faz irracional.

Nós temos, assim, uma explicação aparentemente inexpugnável para a irracionalidade da crença em uma contradição, como ambicionado. (E nem o temido paradoxo de Russell poderia nos fazer crer racionalmente que pode ser racional crer em uma contradição, como quer Priest). ${ }^{25}$

A crença autocontraditória é, portanto, uma forma de irracionalidade, por incoerência, advinda do conteúdo da própria crença (sem fazer, aqui, uma distinção entre forma lógica e conteúdo conceitual) - uma forma de irracionalidade que não envolve um "conflito" da crença dita "irracional" com outras crenças no sistema doxástico do agente, como são os casos paradigmáticos de incoerência.

\section{Absurdidade mooreana: uma explicação epistemológica}

Minha hipótese sobre o problema - a conclusão a que o conjunto de meus argumentos sobre a absurdidade mooreana conduzirá - é a seguinte: É impossível ter-se uma proposição mooreana como objeto de crença, sem que se seja incoerente. Dado que eu suponho que a ausência

${ }^{24}$ Cf. Lehrer 2000.

25 A explicação oferecida aqui me agrada mais que aquela que ofereci em De Almeida 2001. Aquela explicação está comprometida com uma tese evidencialista. Essa não está. Seu apelo (que eu reputo universal) reside, exclusivamente, na conjugação do princípio de distribuição da crença com as suposições epistemológicas feitas quando se discutiu o caso do mordomo. Essa explicação também é, a meu ver, superior àquela que é oferecida em Peter Klein 1985; mas o contraste com a explicação de Klein não pode ser feito aqui. 
de incoerência é condição necessária para a manutenção de um sistema de crenças racionais, uma defesa bem-sucedida da minha hipótese será uma explicação bem-sucedida da irracionalidade da crença mooreana.

Resta, então, aqui, a tarefa de apresentar as teses epistemológicas sobre as quais a minha defesa da hipótese explanatória acima estará baseada. Eu preciso, apenas, que você aceite as seguintes alegações:

(a) Se é racional, para mim, crer que $p$ num momento $t$, então não é racional, para mim, ter, em $t$, qualquer crença que seja contraevidência eficaz (isto é, objeção não-respondida em meu sistema de crenças) para a crença de que $p$.

Essa é a tese subjacente à nossa reação natural quando confrontados com o caso do mordomo, e parece ser intuitivamente irrecusável. Se você abriga, em seu sistema de crenças, uma proposição s cuja verdade reduz, mesmo que muito levemente, a probabilidade epistêmica de que $p$ seja verdadeira, você não pode crer racionalmente que $p-a$ menos que $o$ efeito contraevidencial de s seja neutralizado. No caso do mordomo, nós concluímos que, se você crê que s, você não pode, racionalmente, crer que $p$, porque s é contraevidência para a crença de que $p$ (isto é, torna menos provável a verdade de $p$, porque a existência daquela testemunha é uma indicação, mesmo que inconclusiva, da verdade de não-p) e o efeito solapador que a crença de que s tem sobre sua justificação para crer que $p$ não é, ele próprio, neutralizado por contraevidência. Poderia haver, em seu sistema de crenças, por exemplo, a crença de que (t) a testemunha é casada com o acusado, e o cônjuge de um acusado não é testemunha de defesa confiável. Se t fosse incluída no seu sistema de crenças, a coerência seria restabelecida, e s deixaria de ser contraevidência eficaz para a crença de que $p$ (porque $s \& t$ não é contraevidência para a crença de que $p$ ). Na ausência de uma crença como $t$ - uma crença que neutralize o efeito contraevidencial de $s-s$ é contraevidência eficaz para a crença de que $p$. Isso parece corresponder perfeitamente a nossa reação intuitiva: a crença é racional só se todas as "objeções" a ela estiverem "respondidas" no sistema de crenças do agente (como diria Lehrer). Mesmo a base para a menor suspeição de que $p$ seja falsa deve ser eliminada - ou a crença em $p$ é irracional. Você poderá, é claro, chegar, racionalmente, à conclusão de que a preponderância da evidência recomenda a crença em $p$ - mesmo na ausência de garantias (subjetivas) da verdade de $p$. Mas, se seu comportamento doxástico é racional, essa conclusão já terá implicado a neutralização da força contraevidencial da objeção. (Isto é, você terá evidência de que a preponderância da evidência relevante ao caso recomenda a crença em $p$ ). 
(b) Se é racional, para mim, crer que $p$, e p implica logicamente q, então é racional, para mim, crer que $q$.

Essa é uma versão particularmente fraca (já que implicada pela maioria das versões discutidas na literatura) do conhecido "princípio de fecho" (closure principle) para a racionalidade (ou "justificação") epistêmica. Embora uma versão do princípio tenha sido introduzida, na agenda contemporânea, pelo lendário Gettier, é certo que o princípio é implicitamente aceito desde o reconhecimento do conceito de implicação lógica (nos primórdios da lógica). É difícil imaginar que haja um princípio epistêmico mais fundamental que esse. Recentemente (desde o início dos anos setenta), tentou-se refutá-lo no contexto de tentativas de refutação do ceticismo de inspiração cartesiana. A opinião predominante, na comunidade epistemológica, é a de que essas pretensas refutações fracassaram, e que alguma versão do princípio é irrecusável. ${ }^{26}$ (Veja a seção 4, abaixo, para mais discussão desse princípio).

(c) É racional, para mim, crer que p só se eu nem creio que seja irracional, para mim, crer que $p$, nem creio que seja racional, para mim, crer que não-p.

Há defesas dessa tese na literatura (que, no entanto, não a identificam com clareza). Ernest Sosa fala da necessidade de "coerência ampla", que é a ausência de quaisquer elementos, na vida mental do agente, que possam ser usados, pelo próprio agente, para uma crítica do status epistêmico de suas crenças. ${ }^{27}$ A mesma tese é defendida - ao menos, implicitamente - nas obras de Keith Lehrer e Richard Foley. ${ }^{28}$

Note, ainda, que, se eu aceito a negação dessa tese - e aceito, assim, que seja racional, para mim, crer que $p$, mesmo que eu creia que sou irracional ao fazê-lo - eu teria de tomar como não sendo irracional a crença em um caso da forma (iii). Se a forma (iii) é percebida como sendo paradoxal, então (c) não pode ser recusada consistentemente. Mas, o simples fato de que a negação de (c) é incompatível com a crença de que uma crença da forma (iii) é irracional não nos dá, por si só, uma explicação da irracionalidade de uma crença daquela forma. Eu ainda lhe devo essa explicação.

(d) Se eu creio que creio que p em $t$, então não é racional, para mim, crer que não-p em $t$ (e se eu creio que creio que não-p em $t$, então não é racional, para mim, crer que $p$ em $t$ ).

${ }^{26}$ Cf. Klein 1995, para uma defesa "invariantista" do princípio, e Cohen 1988, para a perspectiva contextualista.

27 Cf. Sosa 1997.

28 Cf. Lehrer, 2000; Foley, 1993 e De Almeida 2002. 
Seria irrazoável esperar que (d) lhe pareça autoevidente. Por isso, eu lhe ofereço o seguinte argumento em defesa dessa tese:

(d1) Se o condicional (d) é falso, então você crê que crê que $p$ e pode ser racional, para você, ao mesmo tempo, manter a crença de que crê que $p$ e adicionar a crença de que não- $p$ em seu sistema de crenças.

(d2) Se o segundo conjunto do consequente de (d1) é verdadeiro, você pode racionalmente crer que $p$ está em seu sistema de crenças enquanto, racionalmente, adiciona não-p ao sistema.

(d3) Nossa suposição mais fundamental sobre racionalidade até aqui é a de que você não pode crer racionalmente que $p$ se a crença de que $p$ é incoerente com seu sistema de crenças - ou seja, se seu sistema de crenças contém evidência eficaz para não-p. ${ }^{29} \mathrm{E} q$ pode ser evidência para $p$ só se a suposta verdade de q probabiliza $p$ (segundo qualquer concepção de probabilidade).

(d4) À luz de (d3), se o consequente de (d2) é verdadeiro, você pode, verazmente, crer que $p$ está em seu sistema de crenças enquanto, racionalmente, adiciona não-p ao sistema (isto é, a verdade do que você já crê, "Eu creio que p", supostamente, não probabiliza a negação do que você acrescenta ao sistema, não-p).

(d5) Se o consequente de (d4) é verdadeiro, você pode, racionalmente, adicionar não-p ao seu sistema de crenças enquanto $p$ está no sistema.

(d6) Mas, o consequente de (d5) é falso, já que, se fosse verdadeiro, você creria racionalmente que não-p ao mesmo tempo em que se tornaria fortemente inconsistente ao ter essa crença, o que nós supusemos ser impossível.

(d7) Assim, através de aplicações sucessivas de modus tollens, nós concluímos que o antecedente de (d1) é falso.

Para quem aceita a tese segundo a qual a inconsistência forte é incompatível com a racionalidade daquela crença que torna um sistema de crenças fortemente inconsistente, a aceitação de (d) deve ser

${ }^{29}$ Nós devemos ignorar, aqui, a questão de se as crenças que você tem, em um determinado momento, são racionais. O que nos interessa, ao considerarmos (d), são as limitações que o sistema de crenças que você mantém em um determinado momento impõe à aquisição de crenças novas. Talvez você jamais devesse ter acreditado que $p$. Mas, se você o fez, a presença de $p$ em seu sistema de crenças impede a inclusão racional de não-p no sistema quando essa inclusão é contemporânea da crença de que $p$. 
inevitável. Qualquer epistemologia sustentável deve ter (d) como uma de suas implicações. ${ }^{30}$

(e) Se eu creio que p em $t$, então, em $t$, é (prima facie) racional, para mim, crer que eu creio que $p$.

Essa é uma tese fundacionista, o que compromete nossa explicação com uma forma muito fraca de fundacionismo. A suposição, aqui, é, simplesmente, a de que a ocorrência de um evento mental torna prima facie razoável, para o agente em cuja vida mental se dá a ocorrência, crer que essa ocorrência se dá.

(f) Se eu creio que $p \& q$, então eu creio que $p$ e creio que $q$.

Como já foi observado, a aceitação desse princípio de distribuição da crença sobre conjunções é universal.

O trabalho feito até aqui nos permite provar, utilizando-nos, simplesmente, da lógica proposicional clássica, que a aceitação de nossas premissas impõe concluir que não se pode ter uma proposição mooreana como objeto de crença sem que nos tornemos incoerentes. No que segue, "Bp" é uma abreviação de "Eu creio que p", e "Rp" abrevia "É (prima facie) racional, para mim, crer que $p$ ". Assim, "RBp" simboliza "É (prima facie) racional, para mim, crer que eu creio que $p$ " e "Bp\&Rp" abrevia "Eu creio racionalmente (prima facie) que $p$ ". O objetivo é mostrar que a crença mooreana não é, prima facie, racional - o que assegura o resultado segundo o qual a crença mooreana é um caso de irracionalidade simpliciter. ${ }^{31}$ Veja:

Sobre (i):
1. $\mathrm{B}(\mathrm{i}) \supset \mathrm{Bp}$
Suposição de (f)
2. $\mathrm{Bp} \supset \mathrm{RBp}$
Suposição de (e)
3. $\mathrm{R}(\mathrm{i}) \supset \mathrm{R} \sim \mathrm{Bp}$
Suposição de (b)
4. $\mathrm{R} \sim \mathrm{Bp} \supset \sim \mathrm{RBp}$
Suposição de (a)
5. $B(i) \& R(i)$
Suposição para Redução ao Absurdo
6. $B(i)$
7. $\mathrm{R}(\mathrm{i})$
5 por Simplificação
8. $\mathrm{B}(\mathrm{i}) \supset \mathrm{RBp}$
5 por Simp.
9. $\mathrm{R}(\mathrm{i}) \supset \sim \mathrm{RBp}$
1, 2 por Silogismo Hipotético
3, 4 por $\mathrm{SH}$

30 A correspondência com Richard Feldman, John Williams e Robert Audi me fez ver que uma versão anterior do argumento em favor de (d) não era suficientemente clara.

31 Uma crença é racional ultima facie se e somente se é racional prima facie e não há contraevidência eficaz para ela na vida mental do agente. Para uma discussão da distinção prima e ultima facie em epistemologia, cf. Señor 1996. 
10. $\mathrm{RBp}$

11. $\sim \mathrm{RBp}$

12. $\sim(B(i) \& R(i))$

Sobre (ii):

1. $\mathrm{B}(\mathrm{ii}) \supset \mathrm{BB} \sim \mathrm{p}$

2. $B B \sim p \supset \sim R p$

3. $\mathrm{R}(\mathrm{ii}) \supset \mathrm{Rp}$

4. $\mathrm{B}(\mathrm{ii}) \& \mathrm{R}(\mathrm{ii})$

5. $\mathrm{B}(\mathrm{ii}) \supset \sim \mathrm{Rp}$

6. B(ii)

7. $\sim \mathrm{Rp}$

8. $\mathrm{R}$ (ii)

9. $\mathrm{Rp}$

10. $\sim(B(i i) \& R(i i))$

Sobre (iii):

1. $\mathrm{Rp} \supset \sim \mathrm{B} \sim \mathrm{Rp}$

2. $\mathrm{B}(\mathrm{iii}) \supset \mathrm{B} \sim \mathrm{Rp}$

3. $R$ (iii) $\supset R p$

4. $B($ iii)\&R(iii)

5. B(iii)

6. $\mathrm{R}$ (iii)

7. $\mathrm{Rp}$

8. $B \sim R p$

9. $\sim \mathrm{B} \sim \mathrm{Rp}$

10. $\sim(B(i i i) \& R($ iii $))$

Sobre (iv):

1. $\mathrm{B}(\mathrm{iv}) \supset \mathrm{BR} \sim \mathrm{p}$

2. $\mathrm{Rp} \supset \sim \mathrm{BR} \sim \mathrm{p}$

3. $\mathrm{R}$ (iv) $\supset \mathrm{Rp}$

4. $B(i v) \& R(i v)$

5. B(iv)

6. $\mathrm{R}(\mathrm{iv})$

7. $B R \sim p$

8. $\mathrm{Rp}$

9. $\sim \mathrm{BR} \sim \mathrm{p}$

10. $\sim(B(i v) \& R(i v))$
6, 8 por Modus Ponens

7, 9 por MP

5-11 por RAA
Suposição de (f)

Suposição de (d)

Suposição de (b)

Suposição para RAA

1,2 por $\mathrm{SH}$

4 por Simp.

5,6 por MP

4 por Simp.

3, 8 por MP

4-9 por RAA

Suposição de (c)

Suposição de (f)

Suposição de (b)

Suposição para RAA

4 por Simp.

4 por Simp.

3,6 MP

2,5 MP

1, $7 \mathrm{MP}$

4-9 RAA

Suposição de (f)

Suposição de (c)

Suposição de (b)

Suposição para RAA

4 por Simp.

4 por Simp.

1, 5 por MP

3, 6 por MP

2, 8 por MP

4-9 por RAA

Como se vê, um conjunto de premissas epistemológicas segundo o qual uma crença não pode ser racionalmente mantida se é incoerente com o sistema de crenças do agente nos dá uma explicação de por que uma 
crença mooreana é irracional. Eu vejo, assim, confirmada nossa hipótese sobre o paradoxo: assim como no caso da crença autocontraditória, o ato de crer em uma proposição mooreana o faz incoerente.

\section{Para concluir: mais problemas, mais soluções}

Para finalizar, eu lhe ofereço uma brevíssima discussão de dois problemas gerados pelo Paradoxo de Moore; um deles, para a epistemologia do testemunho (do qual você já teve uma pista acima); o outro, para a epistemologia do raciocínio.

Não se engane: a forma de irracionalidade exemplificada por proposições mooreanas não é uma extravagância filosófica que possa ser facilmente desconsiderada. Se você prestar atenção a nossas transações lingüísticas mais corriqueiras, com a absurdidade mooreana em mente, você se verá ameaçado por essa forma de irracionalidade com impressionante frequência. Considere, por exemplo, a seguinte cena. Você faz uma visita àquela fábrica sofisticadíssima de produtos eletrônicos, guiado por um cientista renomado. Ao cruzar por um corredor, você vê, através do que lhe parece ser uma janela para o pátio da fábrica, o azul de um céu límpido e observa, então, que o tempo melhorou surpreendentemente, já que chovia quando você chegou à fábrica, uma hora atrás. E o cientista lhe diz: "Na verdade, chove lá fora, mas você crê que não chove, porque o que lhe parece ser uma janela é, de fato, o nosso protótipo de um monitor de plasma espetacularmente realista!" Como você reage a essa asserção do cientista? Se você crê no que ele lhe diz, você toma a proposição expressa pela seguinte sentença como objeto de crença: "Chove lá fora, mas eu creio que não chove, porque o que me parece ser uma janela..." Mas, como nós vimos, essa crença o fará incoerente! $\mathrm{E}$, no entanto, não é óbvio que o agente racional deve ser capaz de se utilizar da asserção do cientista para revisar seu sistema de crenças, perdendo, então, a crença de que o tempo melhorou?!

Em correspondência sobre esse caso, Williams me sugere que nós queremos supor que o testemunho do cientista, ainda que paradoxal para mim, seu destinatário, deve poder ocasionar, em mim, um processo de revisão racional de crenças. Williams está certo quanto a isso, o que nos dá o problema contundente de explicar como isso é possível. Note que parece impossível que se instaure, em mim, o processo inferencial que levará à revisão desejada - se esse for um processo de revisão racional. Supondo-se, como é habitual, que a crença racional na conclusão de um argumento requeira a crença racional em cada premissa do argumento (e ignorando-se, aqui, a aparente exceção representada pelos casos de reductio ad absurdum), se a proposição mooreana veiculada pelo testemunho do cientista for uma das minhas premissas, será uma crença 
irracional minha, e a racionalidade do meu processo inferencial de revisão de crenças estará decisivamente comprometida.

Minha proposta de resolução: não é necessário que nós suponhamos que o meu processo de revisão de crenças tome o conteúdo mooreano do que me foi dito como uma de minhas premissas. Eu posso ter todas as vantagens de acolher o testemunho escorregadio que me foi oferecido, se minha premissa for da seguinte forma: "O cientista acaba de asserir que ambos, $p$ \& eu não creio que $p$ ". Daqui, dado o fato amplamente reconhecido de que a asserção se distribui sobre os conjuntos de uma conjunção, eu posso, sem qualquer problema aparente, inferir que o cientista asseriu que $p$. E, desta última proposição inferida, juntamente com tudo o mais que seja relevante à minha conclusão, posso, finalmente, alcançar o objetivo de fundar a revisão de meu sistema doxástico em crença racionalmente obtida.

Segundo, uma confissão: Embora eu me tenha utilizado, acima, do popular princípio segundo o qual a racionalidade é transmitida, invariavelmente, pela implicação lógica, eu sou um daqueles que não crêem que esse seja um princípio sustentável. Basicamente, Fred Dretske estava certo ao crer que o princípio é falso. ${ }^{32} \mathrm{~A}$ discussão do tópico pode ser muito extensa, e eu vou, aqui, restringir-me a um aspecto dessa discussão.

Observe como o próprio Paradoxo de Moore nos oferece uma refutação dos princípios de fecho epistêmico para ambos, racionalidade (ou "justificação") e conhecimento.

Tenhamos os seguintes princípios em mente:

Distribuição da crença (DC): Se $\mathrm{S}$ crê que $p \& q$, então $\mathrm{S}$ crê que $p$ e S crê que q;

Distribuição da justificação $(D J)$ : Se $\mathrm{S}$ tem justificação para crer que $p \& q$, então $\mathrm{S}$ tem justificação para crer que $p$ e $\mathrm{S}$ tem justificação para crer que $\mathrm{q}^{33}$

Distribuição do conhecimento ( $D K$ ): Se S sabe que $p \& q$, então $\mathrm{S}$ sabe que $p$ e S sabe que $q$.

Eu não imagino que você faça objeção a qualquer desses princípios. Eu pretendo utilizá-los para a recusa dos seguintes princípios de fecho epistêmico:

32 Cf. Dretske 970. Para uma alternativa à abordagem de Dretske que reconhece algum mérito no protesto daqueles que defendem os princípios de fecho epistêmico, cf. meu artigo 2007a.

33 Se não me engano, DJ é explicitamente introduzido na literatura em Klein 1981. Note que eu estou usando "S tem justificação para crer" como sinônimo de "S é racional ao crer". Em nenhum caso é suposto que $\mathrm{S}$ já formou a crença de que $p$. 
Fecho do conhecimento $(F C)$ : Se $\mathrm{S}$ sabe que $p_{1} \ldots p_{\mathrm{n}}(\mathrm{n} \geq 1)$ e $p_{1} \ldots p_{\mathrm{n}}$ implica $q$, então $\mathrm{S}$ sabe que $q$;

e

Fecho da racionalidade $(F R)$ : Se S é racional ao crer que $p_{1} \ldots p_{\mathrm{n}}(\mathrm{n} \geq 1)$ e $p_{1} \ldots p_{\mathrm{n}}$ implica $q$, então $\mathrm{S}$ é racional ao crer que $q$.

Suponha que o (raciocínio cujo conteúdo é o) seguinte argumento tem premissas que são casos de conhecimento:

(i) Tudo que você diz sobre mim é verdadeiro.

(ii) Você diz que, ambos, [p] eu tenho uma doença fatal, mas não creio que tenha tal doença.

(iii) Portanto, eu tenho uma doença fatal, mas não creio que tenha uma doença fatal [ $p$ \& eu não creio que $p$ ].

Agora, veja que, por DK, para que a crença (iii) seja um caso de conhecimento, é necessário que eu saiba que não creio que $p$ (ou seja, o lado direito da conjunção tem de ser objeto de conhecimento). Se eu sei que não creio que $p$, então eu não creio que $p$ (já que o conhecimento é factivo). Mas, ainda por DK, para que (iii) seja um caso de conhecimento, é necessário que eu saiba que $p$ (ou seja, o lado esquerdo da conjunção precisa ser objeto de conhecimento). No entanto, eu não posso saber que $p$ se eu não creio que $p$. Logo, eu não posso saber que $p$. (Essas duas condições necessárias para que eu saiba que (iii) não podem ser simultaneamente satisfeitas.) Logo, FC é falso. (E não pode haver objeção contextualista plausível a essa refutação de FC!).

Suponha, agora, que o seguinte argumento tem premissas verdadeiras que são casos de crença racional (ou "justificada"):

(i) Tudo que você diz sobre mim é verdadeiro.

(ii) Você diz que, ambos, [p] eu tenho uma doença fatal, mas creio que não tenho uma doença fatal.

(iii) Portanto, eu tenho uma doença fatal, mas creio que não tenho uma doença fatal [ $p$ \& eu creio que não-p].

$E$ note que, por $\mathrm{DC}$, se eu creio que (iii), então eu creio que $p$. Se (iii) é uma verdade, então eu creio que não-p (ou seja, o lado direito da conjunção é uma verdade). Mas, por DJ, se eu sou racional ao crer que (iii), então eu sou racional ao crer que $p$. No entanto, se eu creio que não-p, eu não sou racional ao crer que $p$ (conforme já supusemos). Logo, ou (iii) é falsa, ou eu não sou racional ao crer que (iii). Mas, dado que, por hipótese, (i) e (ii) são verdadeiras, e dado que o argumento é inquestionavelmente válido, (iii) é uma verdade. Logo, eu não sou racional ao crer que (iii). Logo, FR é falso. ( $E$, mais uma vez, note a imunidade a 
objeções contextualistas). Isso ameaça, de alguma forma, a análise da absurdidade mooreana oferecida na seção 3, acima? Não! Porque nossas objeções a FR não refutam o seguinte princípio de transmissibilidade da racionalidade pela implicação lógica:

Semifecho da Racionalidade (SR): Se S é ultima facie racional ao crer que $p_{1} \ldots p_{\mathrm{n}}(\mathrm{n} \geq 1)$ e $p_{1} \ldots p_{\mathrm{n}}$ implica $q$, então $\mathrm{S}$ é prima facie racional ao crer que $q$.

Há, na epistemologia contemporânea, o reconhecimento da importância da distinção entre racionalidade prima facie e ultima facie. Muito simplesmente: você é racional prima facie ao crer que $p$ só se tem forte evidência para crer que $p$ (em uma análise evidencialista da noção de racionalidade epistêmica, que é suficiente para nosso propósito aqui). Mas, isso não basta para que sua crença de que $p$ (se você crê que $p$ ) seja um caso possível de conhecimento. É preciso, ainda, que não haja contraevidência para $p$ em sua vida mental. Se não houver, você será racional ultima facie ao crer que $p$.

Note como há, no caso que refuta FR, contraevidência para a crença em (iii): a absurdidade daquela proposição - ou, se você preferir, todo o argumento que eu lhe ofereci, na seção 3 acima, em favor do reconhecimento da absurdidade de (iii). Mas, não deve haver dúvida de que, no caso do argumento que refuta FR, você pode ser ultima facie racional ao crer que (i) e ao crer que (ii). Assim, toda a surpresa que há, ali, deve- se ao fato de que (i) e (ii) transmitem racionalidade prima facie para (iii). A implicação lógica faz a transmissão da racionalidade prima facie. Não o faz, no entanto, para a racionalidade ultima facie. SR sobrevive a esse ataque a FR. Isso teria bastado para que utilizássemos SR acima, quando eu lhe ofereci uma demonstração de como nossos princípios (a)-(f) nos levam a condenar, epistemologicamente, a crença mooreana. Pareceu-me, em todo caso, que lhe conviria uma discussão em separado de como o Paradoxo de Moore pode ser usado em uma refutação de FR. Nossa análise do paradoxo não é autorrefutadora - sejam quais forem, de resto, as suas deficiências.

Nada disso esteve na perspectiva de Moore ou Wittgenstein, ou dos seguidores deles, sobre o problema. O problema pertence à epistemologia contemporânea. ${ }^{34}$

${ }^{34}$ Eu agradeço a Robert Audi, Richard Feldman, Peter Klein, Alexandre Meyer Luz, Roy Sorensen e John Williams pela discussão generosa de muitas das idéias apresentadas neste artigo. A meu colega Roberto Pich, organizador deste volume, agradeço pela motivação para a elaboração deste artigo e pela supervisão extraordinariamente atenta de sua redação final. 


\section{Referências}

COHEN, Stewart. How to be a fallibilist. In: TOMBERLIN, James E. (Ed.). Philosophical Perspectives. Atascadero: Ridgeview, 1988. v. 2, p. 581-605.

DE ALMEIDA, Claudio. Closure, defeasibility and conclusive reasons. Acta Analytica, v. 22, n. 4, p. 301-319, 2007a.

. Moorean absurdity: an epistemological analysis. In: GREEN, Mitchell; WILLIAMS, John (Ed.). Moore's paradox: new essays on belief, rationality and the first person. Oxford: Oxford University Press, 2007b.

The paradox of inference in canonical form. In: KVANVIG, Jonathan (Ed.). Certain Doubts [a blog devoted to matters epistemic]. Waco, 2005. Disponível em: $<$ http://el-prod.baylor.edu/certain_doubts/?p=499>.

. Uma versão do deontologismo epistêmico. In: SOUZA, Draiton Gonzaga de (Org.). Amor scientiae: Festschrift em homenagem a Reinholdo Aloysio Ullmann. Porto Alegre: Edipucrs, 2002. p. 121-135.

What Moore's paradox is about. Philosophy and Phenomenological Research. v. 62, n. 1, p. 33-58, 2001.

DRETSKE, Fred. Epistemic operators. The Journal of Philosophy, v. 67, 1970. Reimpresso in: idem. Perception, Knowledge and Belief. Cambridge: Cambridge University Press, 2000.

FOLEY, Richard. Justified inconsistent beliefs. American Philosophical Quarterly, v. 16, p. 247-258, 1979.

Working without a net: a study of egocentric rationality. Oxford: Oxford University Press, 1993.

GREEN, Mitchell; WILLIAMS, John. Introduction [to Moore's paradox: new essays on belief rationality and the first person]. Oxford: Oxford University Press, 2007.

HARMAN, Gilbert. Change in view: principles of reasoning. Cambridge, MA: MIT Press, 1986.

KLEIN, Peter. Certainty: a refutation of skepticism. Minneapolis: University of Minnesota, 1981.

Skepticism and closure: why the evil demon argument fails. Philosophical

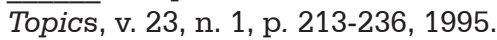

The virtues of inconsistency. The Monist, v. 68, p. 105-135, 1985.

LEHRER, Keith. Theory of knowledge. 2. ed. Boulder, CO: Westview Press, 2000.

MOORE, George Edward. A reply to my critics. In: SCHILPP, P. (Ed.). The philosophy of G. E. Moore. La Salle, Ill.: Open Court, 533-677, 1942.

. Moore's paradox. In: BALDWIN, Thomas (Ed.). G. E. Moore: selected writings. London, New York: Routledge, 1993.

Russell's “Theory of Descriptions". In: SCHILPP, P. (Ed.). The philosophy of Bertrand Russell. La Salle, Ill.: Open Court, 1944. p. 177-225.

POPPER, Karl. What is dialectic? In: . Conjectures and refutations: the growth of scientific knowledge. 5. ed. London: Routledge, 1989. p. 312-335. Reimpressão de: POPPER, Karl. What is dialectic? Mind, v. 49, n. 196, 1940. 
PRIEST, Graham. Contradiction, belief and rationality. Proceedings of the Aristotelian Society, v. 86, p. 99-116, 1986.

SAINSBURY, R. M. Paradoxes. 2. ed. Cambridge, New York: Cambridge University Press, 1995.

SENOR, Thomas. The prima/ultima facie justification distinction in epistemology. Philosophy and Phenomenological Research, v. 56, n. 3, p. 551-566, 1996.

SHOPE, Robert. Gettier problems. In: ROUTLEDGE encyclopedia of philosophy. New York, London: Routledge, 1998.

SOSA, Ernest. Reflective knowledge in the best circles. The Journal of Philosophy, v. 94, p. 410-430, 1997.

WILLIAMS, John. Moorean absurdity and the intentional 'structure' of assertion. Analysis, v. 54, p. 160-166, 1994.

WITTGENSTEIN, Ludwig. Philosophical Investigations. Oxford: Blackwell, 1953. . Remarks on the philosophy of psychology. Oxford: Blackwell, 1980. v. 1. 